\title{
Random Key Chaining (RKC): AES Mode of Operation
}

\author{
Puneet Kumar Kaushal \\ Lovely Professional \\ University \\ Jalandhar-Delhi G.T. Road \\ Phagwara, Punjab (India)
}

\author{
Rajeev Sobti \\ Lovely Professional \\ University \\ Jalandhar-Delhi G.T. Road \\ Phagwara, Punjab (India)
}

\author{
Dr. G. Geetha \\ Lovely Professional \\ University \\ Jalandhar-Delhi G.T. Road \\ Phagwara, Punjab (India)
}

\begin{abstract}
There is a compelling need for a mode of operation that can efficiently provide authenticated encryption at a higher data rate, and is capable of making use of pipelining and parallel processing. This paper describes Random Key Chaining (RKC) block cipher mode of operation that fills this need. RKC mode makes use of Deterministic Random Bit Generator (DRBG) andwith the application of DRBG every block of plaintext is being encrypted with a different key bringing it closer to one-time pad approach. The slight variation of RKC mode can be used as a confidentiality mode that can be used in application like hard-disk compression with reduced computational cost.
\end{abstract}

\section{General Terms}

Security, Authenticated Encryption mode.

\section{Keywords}

Random Key chaining RKC, Deterministic Random Bit Generator DRBG, Confidentiality mode, Authenticated Encryption Mode of Operation, Advanced Encryption Standard AES.

\section{INTRODUCTION}

Among the encryption modes, Counter mode ${ }^{[1]}$ has emerged as a best method for high speed encryption but provides no protection against bit-flip attacks (also called malleability ${ }^{[2]}$ ) because there is no suitable message authentication in this mode. David A. McGrew and John Viega proposed Galois/Counter Mode of Operation ${ }^{[3]}$ that combines counter mode of encryption with Galois Mode of authentication and was an improvement to Carter-Wegman Counter $\mathbf{C W C}^{[4]}$ mode. The key feature in GCM was: the Galois Field multiplication used for authentication can be computed in parallel, thus increasing the throughput in comparison to authentication algorithms that uses chaining mode (like CBC).

GCM comes out to be a good candidate for authenticatedencryption mode of operation and is also implemented in TLS1.2. Vinodh Gopal et al. describes an optimized implementation of GCM that combines functional stitching with novel polynomial multiplication methods, and achieved performance of 2.8 Cycles/byte. This is a new record for GCM performance on Intel processors ${ }^{[5]}$. However Furguson $^{[6]}$ described two weaknesses in the authentication functionality of GCM when it is used with a short authentication tag. The first weakness was construction of targeted cipher text forgery and second weakness reveals authentication key if attacker manages to create successful forgeries ${ }^{[7]}$. CBC-MAC ${ }^{[8]}$ and the modes that use it to provide authentication like OMAC ${ }^{[9]}, \mathbf{E A X} \mathbf{X}^{[10]}$ and $\mathbf{C} \mathbf{C M}^{[11]}$ cannot be pipelined or parallelized, and thus cannot provide higher data rates. In CWC mode of operation, message authentication has circuit depth longer because of additional application of block cipher due to additional post processing step $^{[12]}$. This additional delay would certainly impact its performance on short packets or frames. This leaves behind CWC mode for high speed implementation. Rogaway et al. in his paper ${ }^{[13]}$ described software performance of authenticatedencryption modes (CCM, GCM \&different version of OCB) across variety of platform, and $\mathbf{O C} \mathbf{C B}^{[14]}$ was found to be faster than other modes. However,OCB is covered with multiple intellectual property claims.

Random Key Chaining (RKC) block cipher mode is designed to provide both data authenticity and confidentiality. Confidentiality is provided on plaintext, and authentication is provided on plaintext and cipher text both.

RKC mode has additional useful properties. For every block of plaintext, different key is used for encryption. And these keys are obtained with no extra computational cost (since preprocessing can be done for key stream generation). Variation of encryption-keys for each plaintext block plays an important role. Sometimes what happens, if an attacker successfully breaks one of the cipher text blocks, breaking rest of them becomes relatively easy. Variation in encryption-key for every block of encryption makes differential cryptanalysis more difficult.

Differential cryptanalysis is a form of chosen plaintext attack. What makes it differential is that attacker choses a family of plaintexts $\mathrm{P}_{0}, \mathrm{P}_{1}, \mathrm{P}_{2} \ldots$ where each $\mathrm{P}_{\mathrm{i}}$ is equal to $\mathrm{P}_{0}$ plus some small difference. For many differential attacks difference is taken as 1-bit. So, encrypting plaintexts of 'small bitdifferences' with different key will result in cipher text blocks with 'large hamming distance' in comparison to cipher text blocks that are generatedusing 'same key' again and again.

Another useful property of RKC is that its slight variation can be used to provide only the confidentiality (section 7 , paragraph 3 ), i.e., it can perform as a confidentiality mode efficiently.

\section{TERMS \& DEFINITIONS}

Deterministic Random Bit Generator (DRBG): DRBG produces a pseudorandom sequence of bits from a secret initial value called seed with other possible (optional) inputs.

Entropy: Measure of randomness or disorder in a closed system. Entropy of $\mathrm{X}$ is a mathematical measure of the amount of information provided by an observation of $\mathrm{X}$.

Hamming Distance: It is the difference between two equal length strings. Its value equals to the number of places at which the two bit-strings differ i.e., have different bits.

Hash Function:A mathematical function that maps values from a large domain into a smaller range known as message 
digest or hash value. The function satisfies the following properties:

- It is computationally infeasible to find any input that map to any predefined output.

- It is computationally infeasible any two distinct input that map to the same output.

(B).

Pseudorandom: A process is said to be pseudorandom when the outcome is deterministic, yet also effectively random as long as the internal action of the process is hidden from the observation.

Security Strength: A number associated with the amount of work (no. of operations) required to break a cryptographic algorithm or a system. Security strength i.e. the maximum amount of work required to break the encryption algorithm of $\mathrm{x}$ bits key, using the brute force is $2^{\mathrm{x}}$. For Hash function with message digest size of $\mathrm{x}$ bits, the max amount of work required to break property $\mathrm{A}$ (as defined under the heading Hash Function) is $2^{\mathrm{x}}$ and to break property $\mathrm{B}$ is $2^{\mathrm{x} / 2}$.

Seed: A string of bits that is used as input to a DRBG. The seed determines the internal state of the DRBG and its entropy must be sufficient to support the security strength of DRBG.

Circuit depth: Depth of a circuit is defined as the length of the longest path from the input to the output.

X || Y: Concatenation of two strings $\mathrm{X}$ and $\mathrm{Y}$. Where $\mathrm{X}$ and $\mathrm{Y}$ are both bit-strings.

$\mathbf{X} \oplus \mathbf{Y}$ : Bitwise exclusive-or of two bit-strings $\mathrm{X}$ and $\mathrm{Y}$ of same length.

$\mathbf{E}(\mathbf{X}, \mathbf{Y})$ : Encryption using AES-256 over bit-string Y using key $\mathrm{X}$. Where $\mathrm{X}$ is 256-bits in length and $\mathrm{Y}$ is 128-bits in length.

D(X, Y): Decryption using AES-256 over bit-string Y using key $\mathrm{X}$. Where $\mathrm{X}$ is 256-bits in length and $\mathrm{Y}$ is 128-bits in length.

$|\mathbf{M}|$ : Length of string $\mathbf{M}$, represented in number of bits.

\section{MODE SPECIFICATION}

RKC is generic encryption and authentication block cipher mode. In this paper it is defined with AES encryption algorithm. RKC is defined for only use with 128-bit block cipher, with AES-256 ${ }^{[15]}$ as the encryption algorithm. The RKC idea can easily be extended to other block cipher which will require further definitions.

RKC uses Deterministic Random Bit Generator (DRBG) function for generation pseudorandom bits. DRBG generates same sequence of bits if the same seed is used again. Our DRBG function uses Hash_DRBG as specified in Section
10.1.1 of NIST SP800-90 ${ }^{[16]}$ with SHA-256 ${ }^{[17]}$ as the underlying hash-function. That has:

- $\quad$ Seed length for $\mathrm{DRBG}=440$ bits

(Seed S must have sufficient entropy for generating pseudorandom number).

- $\quad$ Requested number of bits $=256$ bits.

- Maximum number of pseudorandom bits that can be generated without reseeding $\leq 2^{48}$.

Initially, let's say pseudorandom number generated from DRBG is $R_{1}$. Then encryption key $K_{1}$ for the $1^{\text {st }}$ block is obtained as:

$\mathrm{K}_{1}=\mathrm{K}_{0} \oplus \mathrm{R}_{1}$, where $\mathrm{K}_{0}$ is shared secret key between sender and receiver.

\subsection{Inputs}

To send a message sender must provide the following information:

- An Encryption key $\mathbf{K}_{\mathbf{0}}, 32$ bytes (256-bits) in length.

- A Seed S, 55 bytes (440-bits) in length for instantiating DRBG

- Message M, that has $128(\mathrm{n}-1)+\mathrm{y}$ bits. Where $\mathrm{n}$ is the total number of blocks each of size 128-bits and $\mathrm{y}$ are the number of bits in last block.

For better performance, the total number of plaintext blocks to be encrypted (n), must be provided as an input so that appropriate number of key streams can be generated beforehand.

\subsection{Encryption}

The Encryption process is shown in Figure 1.

Let's say $\mathrm{P}_{\mathrm{i}}$ denotes the plaintext block, whereas $1 \leq \mathrm{i} \leq \mathrm{n}$, and $\mathrm{n}$ is total no. of blocks of plaintext. To encrypt a message $M$ of $128(n-1)+y$ bits, we first determine encryption-key stream by:

$$
K_{i}=K_{i-1} \oplus R_{i} \quad \text { Fori }=1, \ldots \ldots, \mathrm{n}
$$

The step performed so far is a part of preprocessing. Each key generated $\left(\mathrm{K}_{\mathrm{i}}\right)$, is used for the encryption of plaintext blocks $\left(\mathrm{P}_{\mathrm{i}}\right)$, for $\mathrm{i}=1$ to $\mathrm{n}$ respectively and this can be executed in parallel.

$$
C_{i}=E\left(K_{i}, P_{i}\right)
$$

The cipher text generated $\left(\mathrm{C}_{\mathrm{i}}\right)$ is XOR-ed with $\mathrm{P}_{\mathrm{i}}$ to produce $\mathrm{X}_{\mathrm{i}}$. This operation is also parallelizable. $\mathrm{X}_{\mathrm{i}}$ as computed below is used to generate authentication tag.

$$
X_{i}=C_{i} \oplus P_{i}
$$




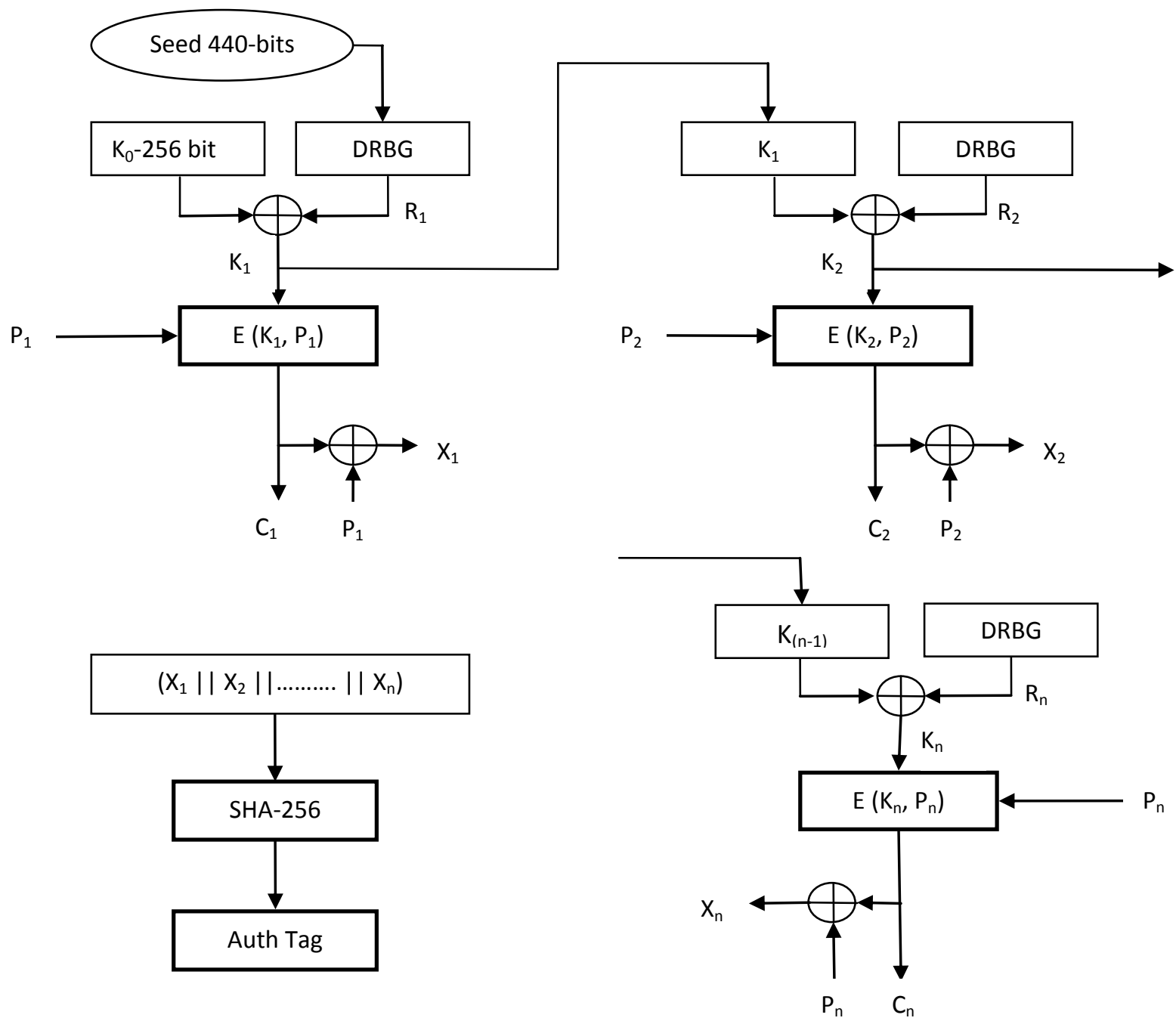

Fig 1: The authenticated encryption operation. For simplicity, first two and then last block of plaintexts are shown.

\subsection{Decryption}

Decryption process is shown in figure 2 .

For decryption, receiver needs Secret Key $\left(\mathrm{K}_{0}\right)$, Seed $\mathrm{S}$ for DRBG instantiation and cipher text. For decryption, key stream $\left(\mathrm{K}_{\mathrm{i}}\right)$ is generated, same as in equation 1 . Then decryption can be executed in parallel for recovering $\mathrm{P}_{\mathrm{i}}$. Whereas,

$$
P_{i}=D\left(K_{i}, C_{i}\right)
$$

At the receiving end, $\mathrm{X}_{\mathrm{i}}$ is also calculated, same as in equation 3 .

\subsection{Authentication}

Authentication part includes:

- Origin: Whether sender is legitimate or not

- Integrity: There is no alteration in cipher text received.
In RKC block cipher mode the authentication is provided on plaintext and the cipher text. For authentication, 'Authentication Tag' $\mathrm{T}$ is used. The plaintext $\left(\mathrm{P}_{\mathrm{i}}\right)$ and cipher text $\left(\mathrm{C}_{\mathrm{i}}\right)$ are XOR-ed to produce 128-bit string $\mathrm{X}_{\mathrm{i}}$, which are concatenated sequentially and processed by hash algorithm SHA-256 ${ }^{[17]}$ to give authentication tag T.

Where,

$$
\mathrm{T}=\operatorname{HASH}\left(\mathrm{X}_{1}\left\|\mathrm{X}_{2}\right\| \ldots \ldots \ldots \mathrm{X}_{\mathrm{n}}\right)
$$

$$
X_{i}=P_{i} \oplus C_{i}
$$

The process of generating authentication data $X_{i}$ can also be executed in parallel. However, for producing $\mathrm{T}$, complete padding $\left(\mathrm{X}_{1}\right.$ to $\left.\mathrm{X}_{\mathrm{n}}\right)$ is required. So, authentication up to much extent is parallelizable.

At receiving end, equation 3 is repeated and authentication tag $\mathrm{T}^{\prime}$ is computed. If both $\mathrm{T}$ and $\mathrm{T}$ ' matches, then cipher text is authenticated. 


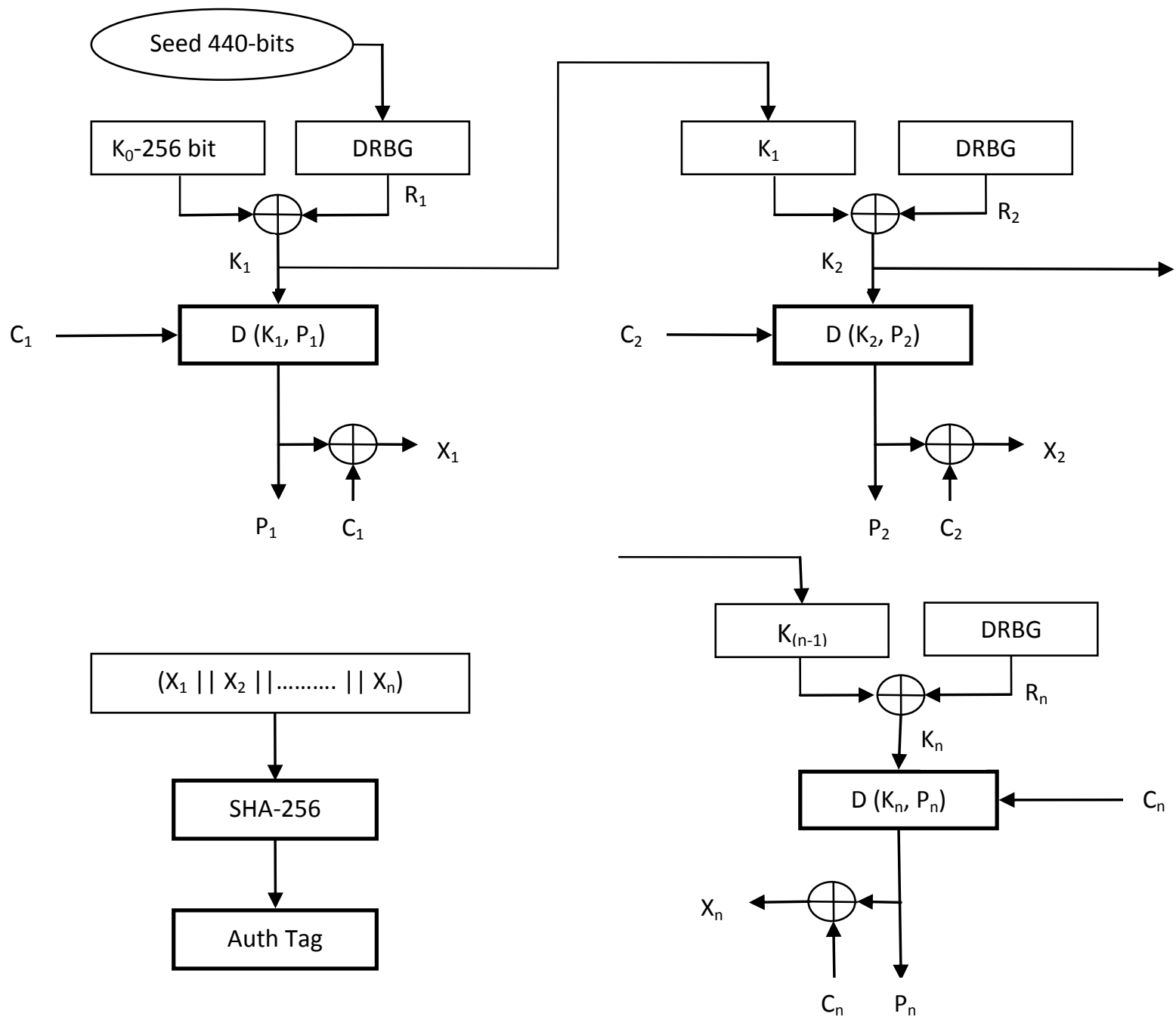

Fig 2: The authenticated decryption operation.First two and then last block of cipher texts are shown.

\subsection{Output}

The final result consists of:

- Cipher textC and

- The Authentication tag $\mathbf{T}$

Cipher text $\left(\mathrm{C}=\mathrm{C}_{1}\left\|\mathrm{C}_{2}\right\| \ldots . . \| \mathrm{C}_{\mathrm{n}}\right)$ is padded with Authentication Tag $\mathrm{T}$ and send to receiver.

\section{ALGORITHM}

Sender and receiver share two keys: $\mathrm{K}_{0}$ (256-bits) and $\mathrm{S}$ (440bits) using a secure channel. $\mathrm{K}_{0}$ is the secret key required by the underlying encryption algorithm (AES-256) and $\mathrm{S}$ is the seed required by HASH_DRBG.

\subsection{Encryption Process}

1. Pre-compute encryption key stream using shared Secret Key and Seed for HASH_DRBG for $n$ (i.e. $\mathrm{N} / 128$ ) blocks (where $\mathrm{N}$ is the message length)

$$
\begin{aligned}
& \text { For } \mathrm{i}=1 \text { to } \mathrm{n} \text { do } \\
& K_{i}=K_{i-1} \oplus R_{i}
\end{aligned}
$$

2. Divide plaintext of $\mathrm{N}$-bits into equal length blocks $\left(\mathrm{P}_{1} \ldots . \mathrm{P}_{\mathrm{n}}\right)$. Where $\left|\mathrm{P}_{\mathrm{i}}\right|=128$.

3. Encrypt each 128 bit $\mathrm{P}_{\mathrm{i}}$ using AES-256 with $\mathrm{K}_{\mathrm{i}}$ as the encryption key. This will be executed in parallel.

4. Perform XOR operation as shown below to generate authentication data $X_{i}$. This will also be executed in parallel

$$
\text { ○ } X_{i}=P_{i} \oplus C_{i}
$$

5. Pad $X_{1}$ to $X_{n}$ and input into SHA-256 to generate Authentication Tag $\mathrm{T}$

$$
\text { ○ } \mathrm{T}=\operatorname{HASH}\left(\mathrm{X}_{1}\left\|\mathrm{X}_{2}\right\| \ldots \ldots \ldots \mathrm{X}_{\mathrm{n}}\right)
$$

Send $\mathrm{C}$ and $\mathrm{T}$ to the receiving end, where $\mathrm{C}=\mathrm{C}_{1} \| \mathrm{C}_{2}$ $\|\ldots \ldots\| C_{n}$

\subsection{Decryption Process}

1. Precompute decryption key stream using shared Secret Key and Seed for HASH_DRBG for n ( i.e. $N^{\prime} / 128$ ) blocks (where $N^{\prime}$ is the cipher text length) 


$$
\begin{aligned}
& \text { For } \mathrm{i}=1 \text { to } \mathrm{n} \text { do } \\
& K_{i}=K_{i-1} \oplus R_{i}
\end{aligned}
$$

2. Divide cipher text of N'-bits into equal length blocks $\left(\mathrm{C}_{1} \ldots \mathrm{C}_{\mathrm{n}}\right)$. Where $\left|\mathrm{C}_{\mathrm{i}}\right|=128$.

3. Decrypt each 128 bit $\mathrm{C}_{\mathrm{i}}$ using AES-256 with $\mathrm{K}_{\mathrm{i}}$ as the decryption key. This will be executed in parallel.

4. Perform XOR operation as shown below to generate authentication data $X_{\mathrm{i}}$. This will also be executed in parallel

$$
\text { ○ } X_{i}=P_{i} \oplus C_{i}
$$

5. Pad $X_{1}$ to $X_{n}$ and input into SHA-256 to generate Authentication Tag T'

$$
\text { ○ } \quad T^{\prime}=\operatorname{HASH}\left(X_{1}\left\|X_{2}\right\| \ldots \ldots \ldots X_{n}\right)
$$

6. Compare T' computed, with Tag T received.

If $\mathrm{T}^{\prime}=\mathrm{T}$, then authentication is complete.

\section{SECURITY}

Theorem 1: For encryption purposes RKC mode for AES is secure against the attacks of $2^{256+440}$ steps of operations provided AES and underlying HASH_DRBG is secure.

Theorem 2:For authentication purposes RKC mode is secure provided underlying SHA-256 is secure.

\section{SUMMARY}

The various parameters of RKC mode of operation is compared with other authenticated encryption modes like CCM, OMAC, EAX, GCM, OCB and CWC and can be found in Annexure I.

\section{CONCLUSION}

By making use of Deterministic Random Bit Generator in RKC mode, every block of plaintext is being encrypted with a different key. So we are closing to One-time Pad (OTP) ${ }^{[18]}$ with practical limit equivalent to period of DRBG nonrepetition (i.e., $2^{48}$ pseudorandom numbers without repetition) and thus there is significant improvement in overall security of the block cipher mode.

One-time pad is also called as the perfect cipher. The idea of OTP was dropped in real world application because it requires a very long key. Key in OTP cannot be used again and so, number of keys required was also very large, and was directly proportional to number of messages. In RKC mode this problem is resolved with the use of two keys, one for encryption and other for seeding. Also, reseeding is not required in this block cipher mode because when pseudorandom number more than $2^{48}$ is generated then shared secret key is expected to change and that would generate a different encryption key.

The slight variation of RKC mode can be used as a confidentiality mode that can be used in application like harddisk compression. For that, we need to skip the process of generating $\mathrm{Xi}$, which is done by XOR-ing $\mathrm{Pi}$ and $\mathrm{Ci}$, and this will also reduce the overall computational cost of the mode. Also, there is no restriction in the plaintext message length when authentication is not required.

\section{REFERENCES}

[1] Lipmaa, H., Rogaway, P., Wagner, D., CTR-Mode Encryption, Comments to NIST concerning AES Modes of Operations, pp. 1-3. Available online at http://csrc.nist.gov/groups/ST/toolkit/BCM/documents/pr oposedmodes/ctr/ctr-spec.pdf.

[2] McGrew, D. A., Nov 15, 2002, Counter Mode Security: Analysis and Recommendations, pp. 2.

[3] McGrew, D. A., Viega, J., June 2005, Galois/CTR Mode of Operation. Available online at http://csrc.nist.gov/groups/ST/toolkit/BCM/documents/pr oposedmodes/gcm/gcm-revised-spec.pdf.

[4] Kohno, T., Viega, J., Whiting, D., May 27, 2003, the CWC Authenticated Encryption (Associated Data) Mode. Available online at http://csrc.nist.gov/groups/ST/toolkit/BCM/documents/pr oposedmodes/cwc/cwc-spec.pdf.

[5] Gopal, V., Ozturk, E., Feghali, W., Guilford, J., Wolrich, G., Dixon, M., August 2010, Optimized Galois-CounterMode Implementation on Intel Architecture Processors, Intel Corporation.

[6] Furguson, N., May 20, 2005, Authentication Weakness in GCM. Available online at http://csrc.nist.gov/groups/ST/toolkit/BCM/documents/c omments/CWC-CM/Ferguson2.pdf.

[7] Furguson, N.,May 20, 2005, Authentication Weakness in GCM, pp. 7-8. Available online at http://csrc.nist.gov/groups/ST/toolkit/BCM/documents/c omments/CWC-CM/Ferguson2.pdf.

[8] Black, J., Rogaway, P., Comments to NIST concerning AES Mode of Operation: A suggestion for handling Arbitrary-Length Messages with CBC-MAC, pp. 1-2, Section 2.

[9] Iwata, T., Kurosawa, K.,Dec 20, 2002, One Key CBC$M A C, \quad$ Available online at http://csrc.nist.gov/groups/ST/toolkit/BCM/documents/pr oposedmodes/omac/omac-spec.pdf.

[10] Bellare, M., Rogaway, P., Wagner, D., April 13, 2003, A Conventional Authenticated-Encryption Mode, Available online http://csrc.nist.gov/groups/ST/toolkit/BCM/documents/pr oposedmodes/eax/eax-spec.pdf.

[11] Housley, R., Whiting, D., Furguson, N., June 3, 2002, Counter with CBC-MAC, Submission to NIST Concerning AES mode of Operation. Available online athttp://csrc.nist.gov/groups/ST/toolkit/BCM/documents/ proposedmodes $/ \mathrm{cm} / \mathrm{ccm}$.pdf.

[12] http://www.zork.org/cwc/draft-irtf-cfrg-cwc-01.txt, Section 2.5.

[13] Krovetz T., Rogaway P., March 21, 2011, the Software Performance of Authenticated Encryption Modes.

[14] Rogaway, P., Bellare, M., Black, J., Krovetz, T.,Aug 3, 2001, OCB: A Block Cipher Mode of Operation for Efficient Authenticated Encryption. Available online at http://csrc.nist.gov/groups/ST/toolkit/BCM/documents/pr oposedmodes/ocb/ocb-spec.pdf. 
[15] Announcing the Advanced Encryption Standard (AES), Federal Information Processing Standards Publication, FIPS 197, Nov 26, 2001.

[16] Barker, E., Kelsey, J., Recommendation for Random Number Generation Using Deterministic Random Bit Generators, March 2007, revised May 2011, NIST Special Publication 800-90, pp. 34-38. Available online at: $\quad$ http://csrc.nist.gov/publications/drafts/80090/Draft_SP800-90A-Rev1_May-2011.pdf.
[17] Announcing Secure Hash Standard, Federal Information Processing Standards Publication, FIPS 180-2, Aug 1, 2002, pp. 18-19, 33-40.

[18] William Stallings, Cryptography and Network Security Principles and Practices, Pearson, Fourth Edition, pp. 4849.

\section{ANNEXURE I}

Table 1: Comparison of RKC with other authenticated modes of operation

\begin{tabular}{|c|c|c|c|c|c|c|c|}
\hline & $\mathrm{CCM}^{[11]}$ & $\mathrm{CWC}^{[4]}$ & EAX $^{[10]}$ & $\mathbf{G C M}^{[3]}$ & $\mathrm{OCB}^{[14]}$ & OMAC $^{[9]}$ & RKC \\
\hline $\begin{array}{l}\text { SECURITY } \\
\text { STRENGTH }\end{array}$ & $\begin{array}{l}2^{128} \text { for key } \\
\text { length larger } \\
\text { or equal to } \\
256 \text { bit. }\end{array}$ & $\begin{array}{l}\text { Provably } \\
\text { secure and its } \\
\text { provable } \\
\text { security } \\
\text { depends only } \\
\text { on the pseudo } \\
\text { randomness of } \\
\text { the underlying } \\
\text { block cipher. }\end{array}$ & $\begin{array}{l}\text { Provably } \\
\text { secured. } \\
\text { Reduction } \\
\text { from block } \\
\text { cipher } \\
\text { pseudorandom } \\
\text { permutation } \\
\text { security. }\end{array}$ & $\begin{array}{l}\text { Relies on random } \\
\text { permutation of the } \\
\text { underlying block } \\
\text { cipher }\end{array}$ & $\begin{array}{l}\text { Provably } \\
\text { secured as } \\
\text { long as the } \\
\text { underlying } \\
\text { block cipher is } \\
\text { secured }\end{array}$ & $\begin{array}{l}\text { OMAC is } \\
\text { variable input } \\
\text { length } \\
\text { pseudorandom } \\
\text { function. So, } \\
\text { depends upon } \\
\text { the input. }\end{array}$ & $\begin{array}{l}2^{256+440} \text { steps of } \\
\text { operations. }\end{array}$ \\
\hline $\begin{array}{l}\text { ERROR } \\
\text { PROPAGAT } \\
\text { ION }\end{array}$ & None & None & None & None & Infinite & None & None \\
\hline $\begin{array}{l}\text { PARALLELI } \\
\text { ZABILITY }\end{array}$ & $\begin{array}{l}\text { Encryption } \\
\text { can be } \\
\text { parallelized }\end{array}$ & $\begin{array}{l}\text { Encryption } \\
\text { parallelizable. } \\
\text { Amount of } \\
\text { parallelism for } \\
\text { the hashing } \\
\text { portion can be } \\
\text { determined by } \\
\text { the } \\
\text { implementer. }\end{array}$ & None & $\begin{array}{l}\text { Encryption: block } \\
\text { level. } \\
\text { Authentication: } \\
\text { bit-level }\end{array}$ & $\begin{array}{l}\text { Encryption } \\
\text { and } \\
\text { decryption are } \\
\text { parallelizable }\end{array}$ & Sequential & $\begin{array}{l}\text { Encryption and } \\
\text { decryption can be } \\
\text { executed in } \\
\text { parallel. And } \\
\text { authentication can } \\
\text { be parallelized up } \\
\text { to greater extent. }\end{array}$ \\
\hline $\begin{array}{l}\text { PRE- } \\
\text { PROCESSIN } \\
\text { G }\end{array}$ & $\begin{array}{l}\text { Encryption } \\
\text { key stream } \\
\text { can be } \\
\text { precompute } \\
\text { d }\end{array}$ & $\begin{array}{lr}\text { CTR } & \text { mode } \\
\text { key } & \text { stream } \\
\text { can } & \text { be } \\
\text { precomputed }\end{array}$ & $\begin{array}{l}\text { Key stream } \\
\text { only }\end{array}$ & $\begin{array}{l}\text { Key stream can be } \\
\text { precomputed. } \\
\text { Fixed parts of IV } \\
\text { can be processed } \\
\text { in advance }\end{array}$ & Limited & Limited & $\begin{array}{l}\text { Key stream } \\
\text { generation for } \\
\text { encryption and } \\
\text { decryption can be } \\
\text { pre-computed. }\end{array}$ \\
\hline $\begin{array}{l}\text { MESSAGE } \\
\text { LENGTH }\end{array}$ & $\begin{array}{l}\text { Octet } \\
\text { aligned } \\
\text { message of } \\
\text { arbitrary } \\
\text { length, up to } \\
2^{8 \mathrm{~L}} \text { octets, } \\
\text { and octet } \\
\text { aligned } \\
\text { arbitrary } \\
\text { additional } \\
\text { authenticate } \\
\text { d data, up to } \\
2^{64} \text { octets. }\end{array}$ & $\begin{array}{l}\text { Up to } 128.2^{(32-} \\
\text { 1) bits. }\end{array}$ & Arbitrary & $\begin{array}{l}\text { Arbitrary message } \\
\text { up to } 2^{39}-256 \\
\text { bits. } \\
\text { Arbitrary } \\
\text { additional } \\
\text { authenticated data } \\
\text { up to } 2^{64} \text { bits. }\end{array}$ & Any bit string & $\begin{array}{l}\text { Arbitrary } \\
\text { length }\end{array}$ & $\begin{array}{l}\text { Message of } \\
\text { arbitrary length up } \\
\text { to } 2^{64} \text { (because of } \\
\text { message input } \\
\text { limit } \\
\text { underlying SHA- } \\
\text { 2)when } \\
\text { authentication is } \\
\text { required. } \\
\text { Otherwise, no } \\
\text { restriction. }\end{array}$ \\
\hline $\begin{array}{l}\text { CIPHERTE } \\
\text { XT } \\
\text { EXPANSION }\end{array}$ & $\begin{array}{l}4,6,8,10, \\
12,14, \text { or } 16 \\
\text { octets } \\
\text { depending } \\
\text { on size of } \\
\text { MAC } \\
\text { selected. }\end{array}$ & $\begin{array}{l}\text { Minimum } \\
\text { possible. }\end{array}$ & Arbitrary & $\begin{array}{l}\text { Cipher text length } \\
\text { is identical to } \\
\text { plaintext length } \\
0 \text { to } 128 \text { bits } \\
\text { required for the } \\
\text { authentication tag. }\end{array}$ & $\begin{array}{l}\text { Minimal } \\
\text { possible }\end{array}$ & Not applicable & $\begin{array}{ll}\text { None. } & \text { Would } \\
\text { require } & \text { further } \\
\text { definitions. } & \end{array}$ \\
\hline
\end{tabular}


International Journal of Applied Information Systems (IJAIS) - ISSN : 2249-0868

Foundation of Computer Science FCS, New York, USA

Volume 1-No.5, February 2012 - www.ijais.org

\begin{tabular}{|c|c|c|c|c|c|c|c|}
\hline $\begin{array}{l}\text { KEY } \\
\text { MATERIAL } \\
\text { / NONCE / } \\
\text { IV }\end{array}$ & $\begin{array}{l}1 \text { key } \\
\text { Nonce/IV }\end{array}$ & $\begin{array}{l}1 \text { key } \\
\text { Nonce/IV }\end{array}$ & $\begin{array}{lc}1 & \text { key } \\
\text { Nonce/IV }\end{array}$ & $1 \mathrm{key}+$ Nonce/IV & $\begin{array}{l}1 \text { key } \\
\text { Nonce/IV }\end{array}$ & $\begin{array}{l}1 \text { key } \\
\text { Nonce/IV }\end{array}$ & 1 key+ IV(Seed) \\
\hline $\begin{array}{l}\text { MEMORY } \\
\text { REQUIREM } \\
\text { ENT }\end{array}$ & $\begin{array}{l}\text { Requires } \\
\text { memory for } \\
\text { encrypt } \\
\text { operation of } \\
\text { the } \\
\text { underlying } \\
\text { block } \\
\text { cipher,plaint } \\
\text { ext, cipher } \\
\text { text } \\
\text { (expanded } \\
\text { for CBC- } \\
\text { MAC), and } \\
\text { a per-packet } \\
\text { counter. }\end{array}$ & $\begin{array}{l}\text { Depends upon } \\
\text { underlying } \\
\text { block cipher. }\end{array}$ & $\begin{array}{l}\text { Small } \\
\text { constants }\end{array}$ & Small constants & Modest & Modest & $\begin{array}{l}\text { Require memory } \\
\text { for plaintext, } \\
\text { cipher text and } \\
\text { key stream } \\
\text { generated for } n \\
\text { blocks, and also } \\
\text { for the } \\
\text { authentication } \\
\text { data }\left(\mathrm{X}_{\mathrm{i}}\right) \text {. }\end{array}$ \\
\hline
\end{tabular}

